\title{
Current Management in Osteoporotic Hip Fracture
}

\author{
Suphot Phruetthiphat ${ }^{1}$ and Ong-art Phruetthiphat ${ }^{2 *}$ \\ ${ }^{1}$ Phanat Nikhom Hospital, Chonburi \\ ${ }^{2}$ Department of Orthopedic, Phramongkutklao Hospital and College of Medicine, Thailand
}

*Corresponding author: Ong-art Phruetthiphat, Orthopedic Department, Phramongkutklao Hospital, Bangkok, Thailand

\begin{tabular}{|c|c|}
\hline ARTICLE INFO & ABSTRACT \\
\hline Received: 蔧 December 20, 2019 & Abbreviations: ACCP: American College of Chest Physician; IF: Internal Fixation; DHS: \\
\hline Published: 幽 January 10, 2020 & Dynamic Hip Screws; MRI: Magnetic Resonance Imaging \\
\hline
\end{tabular}

Citation: Ong-art Phruetthiphat, Suphot Phruetthiphat. Current Management in Osteoporotic Hip Fracture. Biomed J Sci \& Tech Res 24(3)-2020. BJSTR. MS.ID.004063.

\section{Introduction}

Osteoporosis is defined as a skeletal disorder characterized by compromised bone strength predisposing to an increased risk of fracture. Osteoporosis is a devastating disorder with significant physical, psychosocial, and financial consequences [1]. Generally, osteoporotic hip fracture occurring in elderly patient and this is mainly associated with low energy mechanism; fall from standing height [2-5]. The incidence of osteoporotic fracture has projected to increase in worldwide [6-8] and they are associated with morbidity and mortality [9-11]. So appropriate management for hip fracture is really important and it should be done by multidisciplinary team since patient admission until discharge including prevention for the second fracture. Management in hip fracture is mainly classified into non-surgical and surgical treatment. Nonsurgical management is only selected for some patients with severe comorbidities that they cannot tolerate to surgery. However, they tend to have severe complication from immobilization including pneumonia and death within a short period of time.

Therefore, surgery is considered as a first priority for management in patient sustained a hip fracture. Orthopedic surgeon should discuss the overall long-term prognosis of possible decreased mobility and independence as a result of the hip fracture including risk and benefits between nonsurgical and surgical treatment. Hip fracture management is generally divided into 3 stages: preoperative, intraoperative, and postoperative stages.

\section{Preoperative Period [12]}

Physician should access whether patients take any anticoagulant or antiplatelet use and consider stopping them in elective surgery: American College of Chest Physician (ACCP) clinical practice guideline recommends stopping antiplatelet drugs for a minimum of five days before elective surgery [13]. Withholding warfarin and administration of oral or IV vitamin $\mathrm{K}$ is recommended if reversal of the anticoagulant effects of warfarin to permit earlier surgery is deemed appropriate (recommendation B; evidence level $1++$ and level 3) [14, 15]. Low-dose vitamin $\mathrm{K}$ (1-2.5 mg) administered either intravenously or orally, partially reverses the anticoagulant effect of warfarin over 24 hours [15]. FFP should not be used when there was no contraindication for application of vitamin K. Furthermore, low molecular weight heparin (Fondaparinux) should not be used before surgery because of the increased potential for spinal hematoma after spinal or epidural anesthesia (recommendation A) [16].

A Cochrane review examined the use of traction (both skin and skeletal) applied to the injured leg from the time of admission until surgery. This practice is intended to relieve pain and make subsequent surgery easier. However, there was no evidence of any benefit in pain relief or fracture reduction from the routine use of preoperative traction in hip fracture patients [17]. Intravenous 
antibiotic prophylaxis should prescribe within 30 minutes before surgical incision in all patients with hip fracture. A meta-analysis found that compared to placebo, antibiotic prophylaxis significantly reduced the overall wound infection, deep wound and superficial wound infection after hip fracture fixation [18].

\section{Intraoperative Period (Surgical Treatment)}

Hip fractures are simply divided into 2 groups:

1. Intraarticular fracture (femoral neck fracture) and

2. Extra-articular fracture (intertrochanteric fracture) Surgical management in the femoral neck fracture is not similar to the intertrochanteric fracture.

\section{Femoral Neck Fracture}

Singh index was used for evaluating trabecular density in osteoporotic severity [19]. The higher trabecular loss is strongly correlated to higher rate of fixation failure (Figure 1). Surgical fixation for femoral neck fracture depends on degree of displacement. In nondisplaced fracture, dynamic hip screw with side plate is not superior outcome than cannulated screws [20] while there are several treatment options for displaced femoral neck fracture (internal fixation, hemiarthroplasty, and total hip arthroplasty) which depends on age group, bone quality, functional demand, cognitive state, and medical comorbidity (for instance cirrhosis, alcoholism, Parkinsonism) [21]. Internal fixation is usually appropriate in young age patients while old age with frailty patients should consider for arthroplasty. A randomized trial demonstrated both internal fixation (IF) and arthroplasty produce similar final outcomes, but IF has a marginally lower mortality at the expense of an increased re-operation rate $[22,23]$. Generally, patients with preexisting joint disease, medium/high activity levels and a reasonable life expectancy, should have THA rather than hemiarthroplasty as the primary treatment $[23,24]$. Conversely, displaced femoral neck fracture in relatively low functional demands and lack of preexisting hip arthritis should be suitable for hemiarthroplasty. Four good quality systematic reviews found no evidence of superiority of bipolar implants compared to unipolar prosthesis [23,25-27].

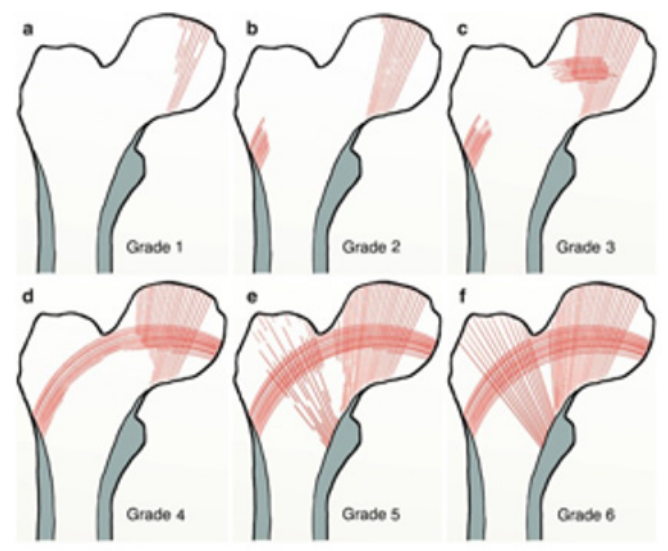

Figure 1: Singh index for osteoporotic severity evaluation.

\section{Intertrochanteric Fracture}

Surgical fixation for a displaced intertrochanteric fracture has several options [28,29]: Dynamic hip screws (DHS), intramedullary device (PFNA), and angle blade plate. First group is considered in stable type, the second group is suitable for unstable type, and the last group is salvage procedure for prior internal fixation failure.

\section{Postoperative management}

Physician should evaluate for risk prevention in many aspects including hip dislocation, infection (surgical site infection, periprosthetic joint infection), deep vein thrombosis, and periprosthetic hip fracture.

1. Hip dislocation can be avoided by external hip protector [30], extreme hip position precaution.

2. Fall prevention can be managed by ambulation with assistive device, hip-quadricep-calf strengthening exercise, evaluate for any associated factors to walking ability including visual problem, proprioceptive sensation, and environment at home.

3. Patients without a contraindication should receive thromboprophylaxis using Fondaparinux for 28 days starting six hours after surgery. Prolongation of thromboprophylaxis with fondaparinux for a further 19-23 days reduced the risk of thrombosis from $35 \%$ to $1.4 \%$ compared with placebo (Evidence level 1++) [31].

4. Mechanical prophylaxis should be considered in suitable patients to reduce the risk of DVT after hip fracture [16]. Cyclic sequential compression and arterial venous $(\mathrm{A}-\mathrm{V})$ foot impulse systems, reduced the risk of DVT by $69 \%$ compared to control.

5. Anti-osteoporotic drug should be taken in all patients after hip fracture surgery guided by Kanis et al [32]. We recommend prescribing any anti-osteoporotic drug with positive effect to increase hip bone mass density as shown in (Table 1).

Table 1: Anti-osteoporotic drug for osteoporotic fracture [33].

\begin{tabular}{|c|c|c|c|}
\hline Agent & Vertebral & Non-Vertebral & Hip \\
\hline Estrogen & + & + & + \\
\hline Alendronate & + & + & + \\
\hline Risedronate & + & + & + \\
\hline Zoledronic acid & + & + & + \\
\hline Ibandronate & + & - & - \\
\hline Denosumab & + & + & - \\
\hline Strontium & + & + & - \\
\hline Raloxifene & + & - & - \\
\hline Calcitonin & + & - & - \\
\hline Teriparatide & + & + & + \\
\hline
\end{tabular}

Recently, the American Academy of Orthopedic Surgeons (2015) has published a usefully clinical guideline for hip fracture 
management into 25 topics (depend on the strength of evidence); 8 topics with strong recommendation, 15 issues with moderate recommendation, and 2 topics with limited recommendation [33, 34].

\section{Strong Recommendation}

1 and 2 for preoperative time period, 3 and 4 for surgical technique, and 5 until 8 for postoperative care.

1. Strong recommendation for use of regional anesthesia "unless a clear and compelling rationale for an alternative approach is present"

2. It is no difference of intraoperative pain control including the relative risks and benefits between general anesthesia and spinal anesthesia.

3. Strong evidence supports a benefit to hemiarthroplasty in patients with unstable (displaced) femoral neck fractures.

4. Strong evidence supports a benefit to apply internal fixation with Cephalomedullary nail for Subtrochanteric or Reverse-oblique intertrochanteric fracture.

5. Strong evidence supports a blood transfusion threshold of no higher than $8 \mathrm{~g} / \mathrm{dL}$ in asymptomatic postoperative hip fracture patients unless a clear and compelling rationale for an alternative approach is present.

6. Intensive physical therapy after hospital discharge is an important issue, with a focus on strength of hip-thigh-calf muscles.

7. Strong evidence supports the use of an interdisciplinary care program in patients with mild to moderate dementia to improve functional outcomes.

8. Multimodal analgesia for decreasing complication from high dose of each drug including minimizing narcotic use to avoid delirium.

\section{Moderate recommendation:}

9 until 11 for preoperative time period, 12 until 18 for surgical technique, and 19 until 23 for postoperative care.

1. In case with suspected femoral neck fracture but fracture line cannot be seen from normal radiography, further MRI (Magnetic Resonance Imaging) is useful for confirm diagnosis.

2. Moderate evidence does not support routine use of preoperative traction for patients with a hip fracture.

3. Moderate evidence indicates that hip fracture surgery within 48 hours of admission is associated with better outcomes.

4. Patient with nondisplaced femoral neck fracture (stable type) should be treated by internal fixation.

5. Patient with displaced femoral neck fracture (unstable type) can be treated by unipolar or bipolar hemiarthroplasty.
6. Displaced femoral neck fracture in patients with high functional demand should be treated by Total hip arthroplasty rather than hemiarthroplasty.

7. Cemented femoral stem is a treatment of choice for a displaced femoral neck fracture in elderly patients (seventy years or older) without severe cardiopulmonary compromise [35].

8. Moderate evidence supports higher dislocation rates with a posterior approach [36].

9. Patients with stable intertrochanteric fracture should be treated by internal fixation (either sliding hip screw or cephalomedullary nail).

10. Patients with unstable intertrochanteric fracture should be treated by cephalomedullary nail.

11. Venous thromboembolism prophylaxis should be prescribed in all patients with hip fracture.

12. Aggressive physical and occupational therapy is used throughout the continuum of care, with a focus on improving balance, mobility, functional activity of daily living, strength, and fall prevention.

13. Nutritional supplement should be added in all patients with hip fracture postoperatively because they can reduce mortality rate.

14. Calcium and vitamin D supplement should be added in all patients with hip fracture because they usually have coexisting vitamin D deficiency.

15. All patients with hip fracture should be transferred for outpatient evaluation of osteoporosis because of their high risk of further fragility fractures).

\section{Limited recommendation}

1. Limited evidence supports not delaying hip fracture surgery for patients on aspirin and/or clopidogrel.

2. Preoperative albumin and creatinine screening for risk assessment in hip surgery.

\section{References}

1. (2000) Osteoporosis prevention diagnosis and therapy. NIH Consensus Statement 17(1): 1-45.

2. Melton LJ, Riggs BL (1985) Risk factors for injury after a fall. Clin Geriatr Med 1: 525-39.

3. Greenspan SL, Myers ER, Maitland LA, Resnick NM, Hayes WC, et al. (1994) Fall severity and bone mineral density as risk factors for hip fracture in ambulatory elderly. JAMA 271(2): 128-133.

4. Tinetti ME, Speechley M, Ginter SF (1988) Risk for falls among elderly persons living in the community. N Engl J Med 319(26): 1701-1707.

5. Tinetti ME, Doucette J, Claus E, Marottoli R (1995) Risk factors for serious injury during falls by elderly person in the community. J Am Geriatr Soc 43(11): 1214-1221. 
6. Ryynanen OP, Kivela SL, Honkanen, Laippala P, Soini P, et al. (1991) Incidence of falling injuries leading to medical treatment in elderly. Public Health 105(5): 373-386.

7. Luukinen, Koski K, Honkanen R (1995) Incidence of injury-causing falls among older adults by place of residence: A population-based study. J Am Geriatr Soc 43(8): 871-876.

8. Tinetti ME (1987) Factors associated with serious injury during falls by ambulatory nursing home residents. J Am Geriatr Soc 35(7): 644-648.

9. Weiss NS, Liff JM, Ure CL, Ballard JH, Abbott GH, et al. (1983) Mortality in women following hip fracture. J Chronic Dis 36(12): 879-882.

10. Sexson SB, Lehner JT (1987) Factors affecting hip fracture mortality. J Orthop Trauma 1(4): 298-305.

11. Bonar SK, Tinetti ME, Speechley M (1990) Factors associated with shortversus long-term skilled nursing facility placement among communityliving hip fracture patients. J Am Geriatr Soc 38(10): 1139-1144.

12. (2009) Scottish intercollegiate guidelines network. Management of hip fracture in older people: A national clinical guideline 9-15.

13. Douketis J, Berger P, Dunn A, Jaffer A, Spyropoulos A, et al. (2008) The perioperative management of antithrombotic therapy: American College of Chest Physicians evidence based clinical practice guidelines ( $8^{\text {th }}$ Edn. $)$, Chest 133(6 Suppl): 299S-339S.

14. Dezee KJ, Shimeall WT, Douglas KM, Shumway NM, O’Malley PG, et al. (2006) Treatment of excessive anticoagulation with phytonadione (vitamin K): A meta-analysis. Arch Intern Med 166(4): 391-397.

15. Watson HG, Baglin T, Laidlaw SL, Makris M, Preston FE, et al. (2001) A comparison of the efficacy and rate of response to oral and intravenous vitamin $\mathrm{K}$ in reversal of over-anticoagulation with warfarin. Br J Haemato 115(1): 145-149.

16. Handoll H, Farrar M, McBirnie J, Tytherleigh Strong G, Milne A, et al. (2002) Heparin, low molecular weight heparin and physical methods for preventing deep vein thrombosis and pulmonary embolism following surgery for hip fractures. The Cochrane library (4): (CD000305).

17. Parker MJ, Handoll HHG (2006) Pre-operative traction for fractures of the proximal femur in adults. Cochrane Database of Systematic Reviews (3): CD000168.

18. South well Keely JP, Russo RR, March I, Cumming R, Cameron I, et al (2004) Antibiotic prophylaxis in hip fracture surgery: A metanalysis. Clin Orthop 419: 179-184.

19. Singh M, Nagrath AR, Maini PS (1970) Changes in trabecular pattern of the upper end of the femur as an index of osteoporosis. J Bone Joint Surg Am 52(3): 457-467.

20. Parker M, Blundell C (1998) Choice of implant for internal fixation of femoral neck fractures: Meta-analysis of 25 randomized trials including 4925 patients. Acta Orthop Scand 69(2): 138-143.

21. Rockwood and Green's Fracture in Adults ( $8^{\text {th }}$ Edn.), Femoral Neck Fractures (Chapter 49): Algorithm for treatment of femoral neck fractures, pp. 2059-2061.

\section{ISSN: 2574-1241}

DOI: $10.26717 /$ BJSTR.2020.24.004063

Ong-art Phruetthiphat. Biomed J Sci \& Tech Res

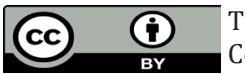

This work is licensed under Creative

Commons Attribution 4.0 License

Submission Link: https://biomedres.us/submit-manuscript.php
22. Davison JN, Calder SJ, Anderson GH, Ward G, Jagger C, et al. (2001) Treatment for displaced intracapsular fracture of the proximal femur. A prospective, randomized trial in patients aged 65 to 79 years. J Bone Joint Surg Br 83(2): 206-212.

23. Parker MJ, Gurusamy K (2006) Internal fixation versus arthroplasty for intracapsular proximal femoral fractures in adults. Cochrane Database of Systematic Reviews (4): CD001708.

24. Rogmark C, Johnell O (2006) Primary arthroplasty is better than internal fixation of displaced femoral neck fractures: a meta-analysis of 14 randomized studies with 2,289 patients. Acta Orthopaedica 77(3): 359-367.

25. Rogmark C, Johnell O (2006) Primary arthroplasty is better than internal fixation of displaced femoral neck fractures: a meta-analysis of 14 randomized studies with 2,289 patients. Acta Orthopaedica 77(3): 359-367.

26. Varley J, Parker MJ (2004) Stability of hip hemiarthroplasties. Int Orthop 28(5): 274-277.

27. Parker MJ, Pervez H (2002) Surgical approaches for inserting hemiarthroplasty of the hip. Cochrane Database of Systematic Reviews (3): CD001707.

28. Audige l, Hanson B, Swiontkowski MF (2003) Implant-related complications in the treatment of unstable intertrochanteric fractures: Meta-analysis of dynamic screw-plate versus dynamic screwintramedullary nail devices. Int Orthop 27(4): 197-203.

29. Parker MJ, Handoll HHG (2008) Gamma and other cephalopodic intramedullary nails versus extramedullary implants for extracapsular hip fractures in adults. Cochrane Database of Systematic Reviews (3): CD000093.

30. Lauritzen JB, Petersen MM, Lund B (1993) Effect of external hip protectors on hip fractures. Lancet 341: 11-13.

31. Eriksson BI, lassen MR, Pentasaccharide iH-FSPI (2003) Duration of prophylaxis against venous thromboembolism with fondaparinux after hip fracture surgery: A multicenter randomized placebo controlled, double-blind study. Arch Intern Med 163(11): 1337-1342.

32. Kanis JA, McCloskey EV, Johansson H, Strom O, Borgstrom F, et al. (2008) National Osteoporosis Guideline Group. Case finding for the management of osteoporosis with FRAX assessment and intervention thresholds for the UK. Osteoporos Int 19(10): 1395-1408.

33. Black DM, Rosen CJ (2016) NEJM 374: 254-262.

34. Karl C (2015) Roberts and W Timothy Brox. "AAOS Clinical Practice Guideline". Journal of American Academy of Orthopedic Surgeons 23(2):138-140.

35. Taylor F, Wright M, Zhu M (2012) Hemiarthroplasty of the hip with and without cement: A randomized clinical trial. J Bone Joint Surg Am 94(7): 577-583.

36. Sköldenberg O, Ekman A, Salemyr M, Bodén H (2010) Reduced dislocation rate after hip arthroplasty for femoral neck fractures when changing from posterolateral to anterolateral approach. Acta Orthop 81(5): 583-587.

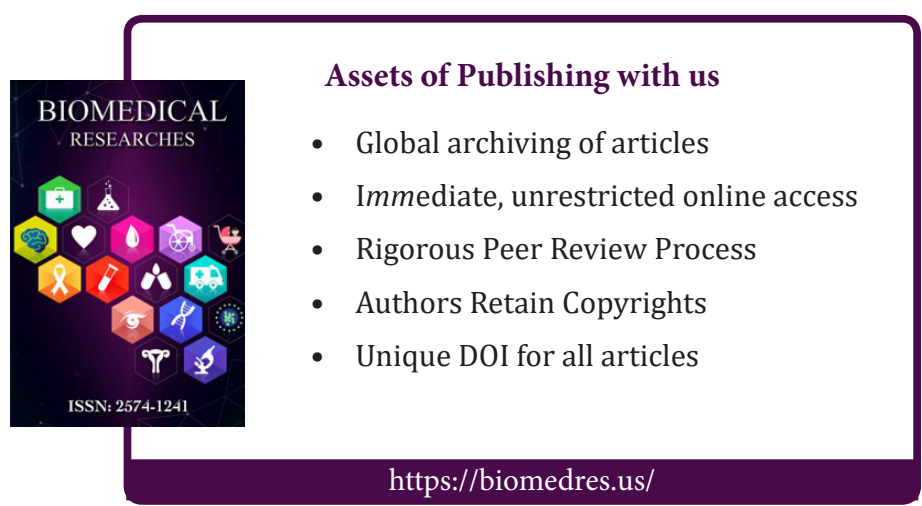

